\title{
Maternal morbidity in Kenya: Measurement, contributions and limitations of DHS data
}

\author{
ANN KIRAGU ${ }^{1}$
}

\begin{abstract}
Résumé
En raison du manque d'information sur les complications liées à la grossesse et l'accouchement au Kenya et dans la plupart des pays d'Afrique subsaharienne, la morbidité maternelle continue d'être une dimension négligée de la santé maternelle, à la différence de la mortalité maternelle. Dans les années 1990, le programme des Enquête Démographique et de Santé (EDS) a collecté des données sur les complications liées à l'accouchement dans un peu moins de 40 pays en développement sur la base des déclarations des femmes. Ce type de données reste sous-utilisé. Cet article analyse la prévalence de la morbidité maternelle auto-déclarée au Kenya ainsi que ses déterminants sur la base de I'EDS 1998, la seule enquête qui a recueilli ce type de données au Kenya. De plus, l'article discute brièvement des approches de la mesure de la morbidité maternelle dans les pays en développement, de leurs forces et de leurs limites. Il s'avère qu'au Kenya le travail prolongé est la complication la plus souvent déclarée en 1998, suivi de I'hémorragie. Des différences significatives entre régions sont observées pour l'hémorragie, la septicémie, et l'éclampsie. Les déclarations de morbidité maternelle sont significativement associées avec la parité, l'assistance à l'accouchement, le groupe ethnique et la province de résidence. L'article conclut qu'en l'absence de systèmes d'état civil adéquats, la morbidité auto-déclarée reste l'approche la plus fiable pour recueillir l'information sur la morbidité maternelle au Kenya et en Afrique subsaharienne.
\end{abstract}

Mots-clés

Morbidité maternelle, complications de l'accouchement, auto-déclarations, biais de sélection, EDS, Kenya.

\section{Summary}

Due to lack of information on complications related to pregnancy and childbirth in Kenya and in most countries in sub-Saharan Africa, maternal morbidity continue to be a neglected dimension of maternal health, unlike maternal mortality. In the 1990s the DHS program collected data on complications related to childbirth in nearly 40 developing countries based on women's reports. This type of data has

1. Le CRIDUP, Université Paris 1 Panthéon-Sorbonne, France. 
been underutilized. This paper analyzes the prevalence of self-reported maternal morbidities in Kenya as well as their determinants using the 1998 Kenya Demographic and Health Survey, the only survey that collected this kind of data in Kenya. The paper also briefly discusses the approaches used in the measurement of maternal morbidity in developing countries, their strengths and limitations. In Kenya it is found that prolonged labor was the most commonly reported complication followed by hemorrhage in 1998. Significant differences between regions are observed in hemorrhage, sepsis, and eclampsia. Reports on maternal morbidity are significantly associated with parity, assistance at delivery, ethnicity, and province of residence. The paper concludes that, because of the absence of adequate vital registration systems, self-reported morbidity remains the most viable approach to collect information on maternal morbidity in Kenya and in Sub-Saharan Africa.

\section{Key words}

Maternal morbidity, delivery complications, self-reports, selection biases, DHS, Kenya.

\section{Introduction}

Maternal mortality and morbidity - a major health problem in sub-Saharan Africa - are the leading cause of death and disability among women of reproductive age (15-49 years) in developing countries (Yamin, Maine, 1999). It is estimated that a vast majority of the world's annual maternal deaths (99\%), occur in these countries (WHO et al., 2012, 2010). The causes of maternal mortality in Sub-Saharan Africa are constantly documented. The five major causes remain hemorrhage, obstructed or prolonged labor, pregnancy-induced hypertension, sepsis, and unsafe abortion, (Koblinsky et al., 2012; Nour, 2008) with hemorrhage being the leading cause of death in Africa (Khan et al., 2006; Say et al., 2014). Among the survivors of these complications are women who suffer devastating maternal disabilities such as obstetric fistulae, pelvic inflammatory disease, and infertility (Balin, 2005). Maternal mortality indicators, notably the maternal mortality ratio, are predominantly used in assessing maternal health in developing countries. By contrast, little attention is devoted to maternal morbidity (Hardee et al., 2012). Neglect to the problem is in part due to the fact that illness related to pregnancy and childbirth is invisible (Ashford et al., 2002). Also, information which is the prerequisite for action is inadequate (AbouZahr, 2003), leading to a «measurement trap» (Campbell, Graham, 1990).

Like most countries in Sub-Saharan Africa, Kenya lacks a full-fledged vital registration statistic system, and therefore other approaches are re- 
quired to measure maternal morbidity. To fill this gap, the DHS program first attempted to collect data on maternal morbidity in the 1990s by including questions on delivery complications in the women's questionnaire in nearly 40 surveys in developing countries. Generally, respondents were asked about the occurrence of specific symptoms during childbirth in the last three or five years prior to the survey, depending on the specific survey. This approach, while providing a valuable source of information to study national and geographical prevalence of maternal morbidities (Souza et al., 2008), suffers from serious limitations notably selection bias, validity, and reliability (Fortney, Smith, 1999).

This paper begins with reviewing various approaches used in the measurement of maternal morbidity in developing countries as well as their strengths and limitations. It concludes that these approaches are all needed in estimating the prevalence of maternal morbidity as well as providing information on associated risk factors in these settings. Indeed, since most maternal deaths occur outside health facilities and causes of these deaths remain unknown, maternal morbidity may be used as an indicator of the quality of health, effectiveness of care, and may help to identify priorities of maternal care (Chhabra et al., 2008). To illustrate the usefulness of one of the approaches, data collected in the 1998 Kenya Demographic and Health Survey (KDHS, 1998) is used to measure the prevalence and determinants of maternal morbidity in the country.

Apart from the 1998 KDHS, which is somehow outdated, there is no other data available to assess the magnitude of maternal morbidity at the national and provincial level in Kenya. Yet, maternal mortality remains persistently high in this country and therefore, there is a need to understand its medical causes.

\section{Measuring maternal morbidity: Contributions and limitations of various approaches}

Maternal or obstetric morbidity can be defined as a «condition that is directly caused by pregnancy, regardless of whether it manifests during or after pregnancy termination; or a condition that existed before pregnancy, but is exacerbated by pregnancy; or a condition whose casual relationship to pregnancy is undetermined» (Adams et al., 2010). This definition takes into account health problems related directly or indirectly to pregnancy and childbirth (Ashford, 2002). Direct obstetric complica- 
tions include obstructed or prolonged labor, hemorrhage, infections, eclampsia and unsafe abortions. Indirect obstetric complications include diabetes, anaemia, malaria and human immunodeficiency virus (HIV). Direct obstetric morbidities are the principal causes of maternal deaths (Khan et al., 2006; Say et al., 2014). In most studies, these pregnancy-related complications are often referred to as 'severe maternal morbidity' (Amaral et al., 2011; Furuta et al., 2012; Kaye et al., 2011; Kayem et al., 2011; Sousa et al., 2008), while in others, "severe maternal morbidity» is used interchangeably with «near-miss» (Ali et al., 2011; Filippi et al., 2000; Nelissen et al., 2013; Oladapo et al., 2005; Say et al., 2004). The World Health Organization (WHO) defines maternal near-miss as a situation in which a woman almost dies but survives a life-threatening complication of pregnancy, childbirth or in the first 42 days following delivery (Say et al., 2009).

Measuring the magnitude of maternal morbidity in most developing countries is a challenge. Firstly, many women deliver at home and therefore complications experienced during childbirth are never recorded for women who survive or those who die. Secondly, vital registration systems are deficient. In Kenya for instance, the registration system does not record data on causes of maternal mortality. In that context, two approaches are generally used to measure maternal morbidity in developing countries: observed and self-reported morbidity.

\section{Observed maternal morbidity}

Observed maternal morbidity involves clinical diagnosis of acute obstetric complications that occur during pregnancy, delivery and the puerperium. Diagnosis is based on signs, symptoms and laboratory findings. The data are derived from maternity records which also collect information on patients' sociodemographic characteristics and antenatal care. In Kenya, several studies have used this approach to estimate obstetric causes of maternal mortality (Chersich et al., 2009; Ukachukwu et al., 2009; Yego et al., 2013). From a medical perspective, this method is the most accurate for providing information about various obstetric complications (Nyblade et al., 2010). Because the data are collected at multiple time points, the nature, incidence and prevalence of maternal morbidities can be studied, as well as their determinants (Forney, Smith, 1999). However, this approach suffers from several drawbacks and biases. Firstly, the results of hospital based studies cannot be generalized as they are not representative of the population at large (Liskin, 1992). Secondly, the approach introduces both diagnosis and selection biases. 
Diagnosis bias is related to a lack of standardization of the criteria used to define obstetric complications. As a result, underlying causes of these complications may be misclassified (Filippi et al., 2000; Haddad et al., 2011). As said earlier, selection bias is due to the fact that more than half of deliveries in most developing countries occur at home, as in the case of Kenya. Therefore, hospital studies only consider women who give birth in hospitals and not those who do not seek obstetric care (Liskin, 1992; Seoane et al., 1998; Stewart, Festin, 1995). Consequently, the approach underestimate the magnitude of maternal morbidity (Nyblade et al., 2010).

\section{Self-reported maternal morbidity}

Self-reported maternal morbidity is typically used in population-or community-based surveys and it relies on women's reporting and perception of major obstetric complications (Amaral et al., 2011; Filippi et al., 2007; Koenig et al., 2007; Sadana, 2000; Souza et al., 2008; Stewart, Festin, 1995). Obtaining information from women's perspectives is crucial for understanding how they perceive maternal complications (Cleland, Harlow, 2003; Ronsmans et al., 1997; Stewart, Festin, 1995). For both large and small scale surveys, the approach is a valuable tool in determining the global burden of obstetric morbidity in the community (Fortney, Smith, 1999; Sadana, 2000; Seoane et al., 1998; Souza et al., 2010; Stewart et al., 1996) as well as its determinants (Midhet, 2007). When data is collected at the national level, this approach offers an opportunity to generalize estimates to the entire population (Sadana, 2000).

Such an approach, while useful, also suffers from limitations and biases. A major problem with this approach is its validity (Filippi et al., 2000; Ronsmans et al., 1997; Seoane et al., 1998; Sloan et al., 2001). To be effective, the measure must accurately identify the women who did not have a condition (specificity) and those that had the condition (sensitivity). Fortney and Smith (1999) argue that small variations in specificity can result in overestimation of the prevalence rate. Where the prevalence is high the possibility to underestimate the phenomenon is even greater. Accordingly, the specificity of the survey questions should be very high to avoid overestimating the true prevalence of obstetric morbidity (Ronsmans et al., 1997). Several studies have been undertaken in developing countries to determine if self-reported symptoms, compared with clinical diagnosis, can predict correctly the occurrence of major maternal morbidities (Filippi et al., 2000; Ronsmans et al., 1997; Seoane et al., 1998; Sloan et al., 2001; Stewart, Festin, 1995; Stewart et al., 
1996). The approach consists of validating interview data on obstetric complications by comparing women's responses with data abstracted from their medical records. This technique showed that eclamptic seizures (Filippi et al., 2000; Seoane et al., 1998) and hemorrhage (Filippi et al., 2000) can be accurately identified (with a recall period of two years). However, the findings of a study on women's recall in Indonesia suggested inconsistencies in the way women report their experiences of childbirth and the way doctors diagnose obstetric problems (Ronsmans et al., 1997).

Self-reports can be undermined by underreporting of maternal morbidities. Since more than half of women in developing countries do not seek care during childbirth, they may not be aware of the complications they experienced and, therefore, asking them to report on complications in clinically defined terms could lead to underreporting of some conditions (Nyblade et al., 2010; Stewart et al., 1996). In addition, underreporting may also be affected by recall biases because women are asked to report information after significant time has elapsed (Fortney, Smith, 1999). In such cases, symptoms that may differ across culture and place of residence (Nyblade et al., 2010) or are the norm in the community may not be recalled (Stewart et al., 1996). Furthermore, this approach only involves the «near-misses». Since those who died cannot be interviewed, and thus, the fatal conditions cannot be captured, this approach also introduces selection biases (Liskin, 1992).

Lastly, a limitation with self-reported maternal morbidity approach is the lack of reliability in the data collected (Fortney, Smith, 1999). It is considered that women's perception of complications related to pregnancy, childbirth and postpartum is inadequate, and therefore, reports of these complications are unreliable (Midhet, 2007). To assess reliability, facility-based data is compared with women's self-reports in a survey. A study in South Africa found that the reliability of self-reported obstetric morbidity was too «modest» and undermined the clinical utility of the findings (Ellison et al., 2000).

\section{Maternal morbidity in Kenya}

In Kenya, the only data on maternal morbidity was collected in 1998 in the context of DHS surveys. Data collection was based on self-reported symptoms of delivery complications that occurred in the last three years preceding the survey. The complications reported comprised of prolonged labor, excessive bleeding, fever and discharge, and, convulsions. It was observed that more than half of the deliveries, as reported by 
women, resulted in one or more maternal morbidities. This high proportion implies that maternal complications constitute a substantial burden for women in Kenya.

Early pregnancies, lack of education, or empowerment, and female genital mutilation, are among the underlying factors of maternal morbidity and mortality. Besides being an important contributor to the overall population growth, adolescent fertility determines the level of maternal morbidity and mortality. According to the 1998 survey, 14\% of adolescents gave birth before their twentieth birthday. To a large extent, this results from a lack of access to contraceptives and health care services including abortion. Literacy, particularly for girls, is important in the improvements of socio-economic status in the society as it determines women's access to health services and prevent the negative outcomes of maternal morbidity (Thaddeus, Maine, 1994). In Kenya, only a quarter of the women interviewed in the 1998 survey had attained secondary education and higher.

The cultural practice of Female Genital Mutilation (FGM) is prevalent in some regions in Kenya. The proportion of genitally mutilated women was quite high at the national level (39\%). The 1998 survey observed statistically significant differences between provinces with Rift valley having the highest proportion of genitally mutilated women (63.2\%) with the least proportion being in Western province (3\%). Genital mutilation is considered an underlying cause of maternal mortality since it predisposes women to complications such as hemorrhage and uterine retention (Oduro et al., 2006). A WHO prospective study in six sub-Saharan Africa countries including Kenya observed that women who were genitally mutilated had a higher risk of postpartum hemorrhage compared to those who were not (WHO et al., 2006).

Pregnancy-related complication can be detected and managed by effectively using maternal health services. In the KDHS-1998 survey, the recommendation to attend to at least four antenatal visits was met. However, utilization of obstetric care was found to be poor. More than half of the women delivered at home particularly in the Rift Valley and Coast province. Accessibility in terms of costs and distance, and availability of qualified birth attendants are major drawbacks especially in the rural areas. Underutilization of health facility in Kenya is mainly linked to these factors.

Obstructed labor is responsible for $9 \%$ of maternal deaths in developing countries (Khan et al., 2006) and its incidence is estimated at 6\% (Dolea, AbouZahr, 2003). Prolonged or obstructed labor occurs when the presenting part of the fetus cannot progress into the birth canal, despite 
strong uterine contractions requiring caesarean section. The most common cause of obstructed labor is cephalo-pelvicdisproportion, when the fetal head is larger than the mother's pelvic brim. Other causes of obstruction include a contracted pelvis, especially among malnourished mothers, and malpresentations. When left untreated, obstructed labor can be fatal to both the mother and the baby. It is also a leading cause of obstetric fistula in Africa making it the most disabling of all maternal conditions. The DHS questionnaire used labor lasting more than 12 hours as an indicator of obstructed labor. Indeed, this indicator has been considered to predict dystocia (Dolea, AbouZahr, 2003) and to be better recalled in a survey (Stewart, Festin, 1995).

Maternal hemorrhage, as defined by WHO, is considered as the loss of $500 \mathrm{ml}$ or more of blood from the genital tract. Based on this definition, it is difficult to determine how accurate the women reports are on maternal hemorrhage especially those who give birth at home. Even at the hospital level, clinical diagnosis through the assessment of blood lost by measurement of collected blood may significantly underestimate the problem. Indeed, a blood loss of $250 \mathrm{ml}$ in women suffering from severe anaemia may be fatal (Kwast, 1991). While the prevalence of postpartum hemorrhage is estimated at $10.5 \%$ in Africa (Calvert et al., 2012), the rate in Kenya is quite high $(23.3 \%)$ with important differences between regions. Hemorrhage is the leading cause of maternal death in the world and accounts for the largest proportion of maternal deaths (34\%) in Africa (Khan et al., 2006). On the other hand, maternal deaths related to hemorrhage varied between 5 and 14\% according to hospital-based studies carried out in Kenya (Nyaboga, 2009; Yego et al., 2013; Ziraba et al., 2009). It is interesting to note that developed countries with low maternal mortality rates have a large proportion of hemorrhagic deaths. For example in France, a recent study found that $18 \%$ of all deaths were from hemorrhage, giving an overall maternal mortality rate of 1.9/ 100'000 live births (Saucedo et al., 2013).

The prevalence of self-reported convulsions in Kenya was on average $16.4 \%$ in the 1998 survey. In the survey questionnaire, the question regarding convulsions was used as an indicator of eclampsia which refers to, a hypertensive disorder of pregnancy, associated with convulsions, and nervous system seizures, leading to unconsciousness and if unattended, to maternal death. In developing countries, the incidence of eclampsia is estimated at 2.3\% (Dolea, AbouZahr, 2003). Studies in Kenya show that eclampsia is a major cause of maternal deaths accounting up to $22 \%$ of deaths in Western province (Yego et al., 2013), and up to $23.7 \%$ in the informal settlements in Nairobi (Ziraba et al., 2009). 
Fever and foul smelling discharge, symptoms of puerperal sepsis, accounted for $16 \%$ of the estimated self-reported morbidity in Kenya in the KDHS-1998 survey. Generally, puerperal infection is used to describe any infection of the genital tract after delivery. Puerperal sepsis is the most common puerperal infection in developing countries which when left untreated could lead to obstetric shock or even death. It is also one of the causes of infertility, pelvic inflammatory disease and bilateral tubal occlusion. Fever is considered a reliable index of the incidence of puerperal infections because most temperature elevation in the puerperium is linked to pelvic infections (Dolea, Stein, 2003).

\section{Data and method}

\section{Data}

The present study is based on data from the 1998 Kenya Demographic and Health Survey (KDHS, 1998). It is the only population-based survey that has collected data on delivery complications in Kenya. The Demographic and Health Survey (DHS) program established in 1984, has conducted over 230 nationally representative household surveys in over 80 developing countries. In the early 1990s, a module on maternal mortality was included in the women's individual questionnaire. The same decade, between 1994 and 1998, the DHS program attempted to collect data on complications related to childbirth in nearly forty developing countries through women's self-reports. In section 4A of the women's individual questionnaire, which involve pregnancy and breastfeeding, DHS included a simplified list of questions of clinically defined signs and symptoms which reflect common obstetric complications such as hemorrhage (excessive bleeding), obstructed/prolonged labor, eclampsia (convulsions) and sepsis (fever with bad smelling discharge). Table 1 shows standard questions that were used in the 1998 KDHS survey and in other developing countries, while Table 2 shows a list of developing countries which collected data regarding maternal morbidities. While this data may constitute a valuable source of information, it has been underutilized. An attempt has been made to study these complications and their determinants using the 1996 Demographic and Health Survey in Brazil (Souza et al., 2008). 
TABLE 1 Delivery related complication standard questions included in KDHS-1998

\begin{tabular}{|l|l|}
\hline Variable & $\begin{array}{l}\text { Question: around the time of birth of (NAME) did you have } \\
\text { any of the following problems? }\end{array}$ \\
\hline Prolonged labor & $\begin{array}{l}\text { Long labor, that is, did your regular contractions last more } \\
\text { than } 12 \text { hours? }\end{array}$ \\
\hline Excessive bleeding & $\begin{array}{l}\text { Excessive bleeding that was so much that you feared it was } \\
\text { life threatening? }\end{array}$ \\
\hline Fever/foul smelling discharge & A high fever with bad smelling vaginal discharge? \\
\hline Convulsions & Convulsion not caused by fever? \\
\hline
\end{tabular}

Some countries, mostly in Asia and Latin America and Caribbean, rephrased or added questions to the standard questions in Table 3. Most of these questions concerned prolonged labor and convulsions (See Table 3). The objective was probably to increase the sensitivity and specificity of questions related to these delivery complications. However, whether these additional questions enabled these countries to capture the intended complication in the specific DHS remains unknown.

TABLE 2 DHS Surveys which included questions concerning delivery complications

\begin{tabular}{|c|c|c|c|c|c|}
\hline Region/Country & $\begin{array}{l}\text { Year of } \\
\text { Survey }\end{array}$ & Region/Country & $\begin{array}{l}\text { Year of } \\
\text { Survey }\end{array}$ & Region/Country & $\begin{array}{l}\text { Year of } \\
\text { Survey }\end{array}$ \\
\hline \multicolumn{2}{|l|}{ Sub-Saharan Africa } & \multicolumn{2}{|l|}{ Asia } & \multicolumn{2}{|c|}{ Latin America and Caribbean } \\
\hline Cameroun & 1998 & Bangladesh & 1996 & Bolivia & 1994 \\
\hline Central Africa Republic & 1994-95 & Indonesia & 1994 & Bolivia & 1996 \\
\hline Chad & $1996-97$ & Indonesia & 1997 & Bolivia & 1998 \\
\hline Comoros & 1996 & Jordan & 1997 & Brazil & 1996 \\
\hline Eritrea & 1995 & Kazakhstan & 1995 & Colombia & 1995 \\
\hline Kenya & 1998 & Kyrgyzstan & 1997 & Dominican Republic & 1996 \\
\hline Madagascar & 1997 & Nepal & 1996 & Guatemala & 1995 \\
\hline Mali & $1995-96$ & Philippines & 1998 & Haiti & 1994-95 \\
\hline Mozambique & 1997 & Turkey & 1998 & Nicaragua & 1998 \\
\hline Niger & 1998 & Uzbekistan & 1996 & Peru & 1996 \\
\hline Nigeria & 1999 & Vietnam & 1997 & & \\
\hline Tanzania & 1996 & Yemen & 1997 & & \\
\hline Togo & 1998 & & & & \\
\hline Uganda & 1995 & & & & \\
\hline Zambia & 1996 & & & & \\
\hline Zimbabwe & 1994 & & & & \\
\hline Zimbabwe & 1999 & & & & \\
\hline
\end{tabular}




\section{Data analysis}

The KDHS-1998 dataset was a nationally representative stratified sample. Stratification was achieved by separating each region into urban and rural areas. Samples were selected independently in each sampling stratum, by two-stage selection. Some geographical areas were oversampled. Only women who were usual residents of a selected household or who slept in a selected household the night before the survey were eligible for the survey. In total, the sample was composed of 7'881 women of reproductive age (15-49 years). Among these women, a sample of 3'058 women who had a live birth in three years preceding the survey was drawn. Given the sample design, the data was weighted to ensure that the sample was representative at the national level while enabling comparison between geographic regions.

Data analysis was carried out in three stages. Firstly, sociodemographic and obstetric characteristics of all women who had a live birth in the last three years were studied based on their geographical region. Chisquare test was used to compare proportions among these regions and a p-value of 0.05 was considered significant. Secondly, the prevalence of the various types of self-reported maternal morbidities as well their patterns were studied. Thirdly, logistic regression analysis was used to study the factors associated with self-reported maternal morbidity. It was postulated that reports on obstetric complications were influenced by the age of a woman at the time of birth, parity, assistance at delivery, ethnicity, and genital mutilation. Geographic residence was not included in the model due to high degree of collinearity with ethnicity. 
TABLE 3 DHS Surveys with a question concerning delivery complications, changes in phrasing and additional questions by country and region

\begin{tabular}{|c|c|c|c|}
\hline $\begin{array}{l}\text { Region/ } \\
\text { Country }\end{array}$ & $\begin{array}{l}\text { Year of } \\
\text { Survey }\end{array}$ & Changes in phrasing & Additional questions \\
\hline \multicolumn{4}{|c|}{ Sub-Saharan Africa } \\
\hline Cameroun & 1998 & & $\begin{array}{l}\text { Incontinence or other/difficulty } \\
\text { walking/other }\end{array}$ \\
\hline Togo & 1998 & $\begin{array}{l}\text { Convulsions not caused by fever so much that } \\
\text { you feared that it was life threatening? }\end{array}$ & \\
\hline Zimbabwe & $\begin{array}{l}1994- \\
1999\end{array}$ & & $\begin{array}{l}\text { Any other complications? If yes: } \\
\text { what kind of complications? }\end{array}$ \\
\hline \multicolumn{4}{|l|}{ Asia } \\
\hline \multirow[t]{3}{*}{ Indonesia } & \multirow[t]{3}{*}{$\begin{array}{l}1994- \\
1997\end{array}$} & $\begin{array}{l}\text { Labor that is the strong and regular contractions } \\
\text { lasting more than one day and one night? }\end{array}$ & $\begin{array}{l}\text { Any other complications? If yes: } \\
\text { what kind of complications? }\end{array}$ \\
\hline & & $\begin{array}{l}\text { A lot more vaginal bleeding than normal follow- } \\
\text { ing child-birth (more than three clothes)? }\end{array}$ & \\
\hline & & Convulsions with loss of consciousness? & \\
\hline Jordan & 1997 & $\begin{array}{l}\text { Up to } 42 \text { days after the birth of (NAME), did you } \\
\text { have any of the following problems? }\end{array}$ & \\
\hline Kazakhstan & 1995 & $\begin{array}{l}\text { Long labor, that is did your regular contractions } \\
\text { last more than } 18 \text { hours? }\end{array}$ & Early rupture of amniotic sac? \\
\hline Kyrgyzstan & 1997 & $\begin{array}{l}\text { Long labor, that is did your regular contractions } \\
\text { last more than } 18 \text { hours? }\end{array}$ & Early rupture of amniotic sac? \\
\hline Uzbekistan & 1996 & $\begin{array}{l}\text { Long labor, that is did your regular contractions } \\
\text { last more than } 18 \text { hours? }\end{array}$ & Early rupture of amniotic sac? \\
\hline \multicolumn{4}{|c|}{ Latin American and Caribbean } \\
\hline Bolivia & $\begin{array}{c}1994- \\
1996- \\
1998\end{array}$ & $\begin{array}{l}\text { Convulsions or seizures with or without loss of } \\
\text { consciousness? }\end{array}$ & $\begin{array}{l}\text { Any other complications? If yes: } \\
\text { what kind of complications? }\end{array}$ \\
\hline Brazil & 1996 & $\begin{array}{l}\text { Convulsions with or without loss of conscious- } \\
\text { ness? }\end{array}$ & High blood pressure \\
\hline Colombia & 1995 & & $\begin{array}{l}\text { Any other complications? If yes: } \\
\text { what kind of complications? }\end{array}$ \\
\hline Guatemala & 1995 & $\begin{array}{l}\text { Convulsions or seizures with or without loss of } \\
\text { consciousness? }\end{array}$ & \\
\hline Nicaragua & 1998 & & Swellings of hands and feet. \\
\hline
\end{tabular}

\section{Results}

\section{Socio-demographic data}

A total of 7'881 women of reproductive age (15-49 years) were interviewed. Among these women, 3'058 had at least one pregnancy resulting to 3'525 live births in the three years preceding the survey. After weighting, a total of 3'007 women and 3'459 live births were obtained. Table 4 shows background characteristics of the women studied, by province. 
TABLE 4 Percent distribution of women with at least one live-birth in the three years preceding the survey according to selected background characteristics, by province

\begin{tabular}{|c|c|c|c|c|c|c|c|c|}
\hline \multirow[b]{2}{*}{ Background Characteristics } & \multicolumn{7}{|c|}{ Province } & \multirow[b]{2}{*}{ Total } \\
\hline & Nairobi & Central & Coast & Eastern & Nyanza & Rift Valley & Western & \\
\hline \multicolumn{9}{|l|}{ Maternal age } \\
\hline$<20$ & 12.4 & 9.0 & 15.6 & 13.1 & 17.4 & 13.0 & 14.4 & 13.9 \\
\hline $20-29$ & 70.5 & 64.0 & 54.4 & 58.6 & 54.4 & 55.0 & 52.3 & 56.9 \\
\hline $30-39$ & 17.1 & 23.8 & 24.9 & 24.5 & 23.9 & 28.3 & 29.5 & 25.4 \\
\hline $40-49$ & 0.0 & 3.4 & 5.2 & 3.7 & 4.5 & 3.6 & 3.8 & 3.7 \\
\hline \multicolumn{9}{|l|}{ Marital status } \\
\hline Married & 79.1 & 79.6 & 85.2 & 83.9 & 80.3 & 86.0 & 88.6 & 83.5 \\
\hline Not married & 20.7 & 20.4 & 15.0 & 16.1 & 19.8 & 14.1 & 11.6 & 16.4 \\
\hline \multicolumn{9}{|l|}{ Education } \\
\hline No education & 0.0 & 5.0 & 34.0 & 8.5 & 7.0 & 13.6 & 10.5 & 10.9 \\
\hline Primary level & 48.5 & 69.4 & 50.0 & 68.0 & 68.4 & 63.8 & 61.2 & 63.6 \\
\hline Secondary level & 41.9 & 25.1 & 15.2 & 21.6 & 23.9 & 20.7 & 26.4 & 23.6 \\
\hline Higher & 9.3 & 0.7 & 0.8 & 1.8 & 0.7 & 1.9 & 2.0 & 1.9 \\
\hline \multicolumn{9}{|l|}{ Occupation*** } \\
\hline Working & 53.3 & 45.3 & 34.3 & 51.4 & 76.0 & 63.3 & 51.6 & 57.9 \\
\hline Not working & 46.6 & 54.8 & 65.8 & 48.2 & 24.1 & 36.5 & 48.3 & 41.9 \\
\hline \multicolumn{9}{|l|}{ Religion } \\
\hline Catholic & 32.4 & 29.1 & 11.7 & 36.1 & 28.1 & 27.5 & 20.3 & 27.4 \\
\hline Protestant/other Christian & 60.0 & 69.5 & 27.0 & 60.8 & 70.3 & 67.8 & 76.6 & 64.5 \\
\hline Muslim & 6.7 & 1.0 & 46.5 & 2.2 & 0.8 & 0.0 & 2.7 & 5.2 \\
\hline No religion & - & 0.6 & 14.3 & 0.7 & 0.2 & 4.0 & 0.1 & 2.4 \\
\hline Other religion & - & - & 0.2 & 0.3 & 0.8 & 0.4 & 0.4 & 0.4 \\
\hline \multicolumn{9}{|l|}{ Genital mutilation*** } \\
\hline Mutilated & 17.1 & 46.2 & 15.4 & 48.1 & 38.0 & 63.2 & 2.9 & 39.2 \\
\hline Non mutilated & 82.9 & 53.4 & 84.6 & 50.0 & 62.1 & 36.9 & 96.7 & 60.3 \\
\hline Weighted Total & (193) & $(279)$ & $(244)$ & (510) & (658) & (751) & (369) & (3007) \\
\hline Unweighted Total & (105) & (258) & $(462)$ & (427) & (545) & $(866)$ & (395) & (3058) \\
\hline
\end{tabular}

$* * * p<0.001$.

No statistical significant differences were found concerning maternal age, education, marital status, and religion, among the provinces. More than half of the births occurred at the optimum child-bearing age, 20-29 years. A small proportion of the women studied had never been to school (10.9\%) with Coast province having the highest proportion of uneducated women (34\%). The respondents were predominantly protestants $(64.5 \%)$ and $2.4 \%$ reported not practicing any religion. Statistically significant differences were observed between provinces concerning occupation. More than half of the women studied reported that they were working. The highest proportion of these women was observed in Nyanza province $(76 \%)$ and the lowest in the Coast province (34.3\%). A significant proportion of the respondents were genital mutilated (39.2\%). Rift Valley province had the highest proportion of genital muti- 
lated women, while the lowest proportion of these women was observed in Western province (2.9\%).

\section{Obstetric characteristics}

Table 5 shows characteristics of obstetric care received during pregnancy. The WHO recommends at least four prenatal visits during pregnancy, delivery with a qualified professional and in a health facility. The women studied had a mean number of prenatal visits estimated at 4.2 visits during their pregnancy. At the provincial level, all provinces met the average recommended number of visits except Nyanza province which was slightly below average (3.9\%). While prenatal care seemed satisfactory, both at the national and provincial level, it was not the case with the place of delivery. Nationally, more than half of the women $(56.7 \%)$ delivered at home. At the provincial level, significant differences were observed among the provinces with Western province having the highest proportion of women who delivered at home (72.4\%). Nairobi and Central provinces had the least number of women, less than a third, who delivered at home.

With regard to assistance provided at delivery, $48.3 \%$ of women were assisted by trained personnel, $35.9 \%$ by a nurse or midwife and $12.4 \%$ by a doctor. Again, significant differences were observed between the provinces. Nairobi and Central provinces had the highest proportion of women being assisted by trained personnel at delivery while Western province had the lowest. More than half of the women in Nairobi and Central provinces reported having delivered with the help of a nurse or midwife (58.1\% and 55.9\%, respectively), $40.7 \%$ in Eastern and less than a third in the other provinces. The majority of women in the Coast and Rift Valley provinces delivered with the help of a relative $(41.5 \%$ and $34.5 \%$, respectively) while Western province had the largest proportion of women who delivered alone (17.7\%). 
TABLE 5 Characteristics of obstetric care per pregnancy by geographical regions of Kenya

\begin{tabular}{|c|c|c|c|c|c|c|c|c|}
\hline \multirow[b]{2}{*}{ Background Characteristics } & \multicolumn{7}{|c|}{ Province } & \multirow[b]{2}{*}{$\begin{array}{l}\bar{\pi} \\
\stackrel{0}{\circ}\end{array}$} \\
\hline & $\begin{array}{l}\frac{0}{0} \\
\frac{0}{\pi} \\
2\end{array}$ & 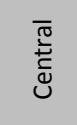 & \begin{tabular}{l}
\multirow{n}{0}{} \\
0 \\
0
\end{tabular} & 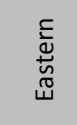 & $\underset{\substack{\mathbb{N} \\
\frac{1}{N}}}{Z}$ & 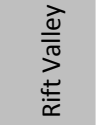 & $\begin{array}{l}\frac{5}{d} \\
\stackrel{ \pm}{y} \\
\stackrel{d}{3}\end{array}$ & \\
\hline Mean number of prenatal visits & 5.4 & 4.5 & 4.2 & 4.2 & 3.9 & 4.2 & 4.7 & 4.2 \\
\hline $95 \% \mathrm{Cl}$ & $\begin{array}{l}4.8- \\
5.9\end{array}$ & $\begin{array}{l}4.1- \\
4.8\end{array}$ & $\begin{array}{l}3.9- \\
4.6\end{array}$ & $\begin{array}{l}3.9- \\
4.5\end{array}$ & $\begin{array}{l}3.7- \\
4.2\end{array}$ & $\begin{array}{c}4.0- \\
4.5\end{array}$ & $\begin{array}{l}4.4- \\
4.9\end{array}$ & $\begin{array}{l}4.2- \\
4.4\end{array}$ \\
\hline \multicolumn{9}{|l|}{ Mode of delivery } \\
\hline Viginal & 87.2 & 89.1 & 93.1 & 91.9 & 98.1 & 91.2 & 96.0 & 93.2 \\
\hline Cesarean section & 12.8 & 10.8 & 6.9 & 8.0 & 1.9 & 8.8 & 3.9 & 6.8 \\
\hline \multicolumn{9}{|l|}{ Place of delivery*** } \\
\hline Home & 23.1 & 29.6 & 65.5 & 50.0 & 62.4 & 63.0 & 72.4 & 56.7 \\
\hline Health facility & 76.7 & 70.4 & 34.5 & 49.8 & 37.6 & 36.8 & 27.4 & 43.2 \\
\hline \multicolumn{9}{|l|}{ Assistance at delivery*** } \\
\hline Doctor & 32.5 & 15.3 & 14.3 & 13.4 & 7.8 & 11.5 & 7.3 & 12.4 \\
\hline Nurse/midwife & 58.1 & 55.9 & 28.5 & 40.7 & 34.4 & 28.6 & 26.5 & 35.9 \\
\hline $\begin{array}{l}\text { Trained traditional birth at- } \\
\text { tendant }\end{array}$ & 3.3 & 3.2 & 11.6 & 16.5 & 15.7 & 5.2 & 24.4 & 12.1 \\
\hline Traditional birth attendant & 4.2 & 1.1 & 10.6 & 15.1 & 10.3 & 13.1 & 5.2 & 10.0 \\
\hline Relative & 11.9 & 16.0 & 41.5 & 17.9 & 24.5 & 34.5 & 20.1 & 25.2 \\
\hline No one & 4.2 & 10.7 & 2.8 & 5.0 & 16.1 & 8.3 & 17.7 & 10.2 \\
\hline Weighted Total & $(215)$ & $(306)$ & $(283)$ & $(584)$ & (753) & $(867)$ & $(451)$ & (3459) \\
\hline Unweighted Total & $(117)$ & $(282)$ & (533) & $(484)$ & $(624)$ & $(1002)$ & $(483)$ & (3525) \\
\hline
\end{tabular}

\section{Women's reports on delivery complications}

Women who had one or more live births in the three years before the survey were asked whether they had experienced any of the listed complications in the questionnaire during childbirth. Table 6 shows the prevalence of self-reported complications by geographic region. As shown in the Table, the most commonly reported complications were symptoms of prolonged labor (34.5\%) followed by excessive bleeding $(23.3 \%)$. Other complications such as high fever/discharge and convulsions accounted for 16 and $16.4 \%$, respectively of the total reported complications.

The significance of specific types of complications varied across provinces. For example, symptoms of excessive bleeding were most common in Nairobi province $(31.6 \%)$ whereas high fever and discharge were prevalent in Eastern province (22.4\%) and convulsion in the Rift Valley province $(27.3 \%)$. 
TABLE 6 Prevalence of reported maternal morbidity according to geographic regions, Kenya 1998

\begin{tabular}{|c|c|c|c|c|c|c|c|c|}
\hline & \multicolumn{7}{|c|}{ Province } & \\
\hline Type of complication & $\begin{array}{l}\frac{\overline{0}}{0} \\
\frac{\sqrt{n}}{2} \\
z\end{array}$ & 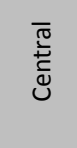 & $\begin{array}{l}\text { 艹 } \\
\text { ర̊ } \\
0\end{array}$ & 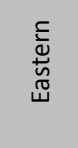 & $\begin{array}{l}\frac{\pi}{N} \\
\frac{\pi}{\pi} \\
\sum\end{array}$ & 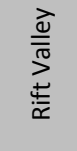 & 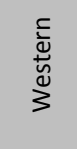 & $\begin{array}{l}\frac{\pi}{0} \\
\stackrel{0}{\frac{0}{7}} \\
\frac{\pi}{2}\end{array}$ \\
\hline Prolonged labor & 34.2 & 24.4 & 34.6 & 37.6 & 35.2 & 32.9 & 39.6 & 34.5 \\
\hline Excessive bleeding*** & 31.6 & 9.0 & 21.8 & 26.7 & 22.6 & 24.3 & 24.6 & 23.3 \\
\hline $\begin{array}{l}\text { High fever and dis- } \\
\text { charge*** }\end{array}$ & 12.0 & 6.8 & 11.6 & 22.4 & 18.6 & 15.2 & 16.2 & 16.0 \\
\hline Convulsions $* * *$ & 23.9 & 6.9 & 15.2 & 13.2 & 8.2 & 27.3 & 17.2 & 16.4 \\
\hline Weighted Total & (215) & (305) & (283) & (584) & (753) & $(864)$ & $(450)$ & (3454) \\
\hline Unweighted Total & (117) & (280) & (532) & (484) & (624) & (997) & (483) & (3517) \\
\hline
\end{tabular}

$* * * \mathrm{p}<0.001$

a There were 8 missing values.

\section{Patterns of women's reporting of maternal complications}

Questions on maternal morbidity were composed of a listing of symptoms of complications that occurred during childbirth and the interviewed women could report on multiple responses. Combining these symptoms gives a better picture of severe complications. As shown in Table 7 below, more than half of the women reported one or more of the listed complications. Of the total number of pregnancies, $52.2 \%$ of the women reported at least one complication, of which $50.4 \%$ reported one complication while $49.6 \%$ reported two or more complications. The results indicate that prolonged labor was a major cause of most severe complications in Kenya while convulsion was the least prevalent complication. $12 \%$ of women who reported having experienced prolonged labor also experienced excessive bleeding which implies that the bleeding was caused by prolonged labor. As a single symptom, convulsions were reported by $5.9 \%$ of women. 
TABLE 7 Patterns of self-reported maternal morbiditya

\begin{tabular}{|l|c|c|}
\hline Reported complication & $\begin{array}{c}\text { Weighted } \\
\text { Cases }\end{array}$ & $\begin{array}{c}\text { Percentage prevalence } \\
\text { of weighted cases }\end{array}$ \\
\hline Single cases & 492 & 27.3 \\
\hline Prolonged labor & 197 & 10.9 \\
\hline Excessive bleeding & 115 & 6.3 \\
\hline High fever \& discharge & 106 & 5.9 \\
\hline Convulsions & 910 & 50.4 \\
\hline Total single cases & & \\
\hline Multiple cases & 217 & 12.0 \\
\hline Prolonged labor + Excessive bleeding & 94 & 5.2 \\
\hline Prolonged labor + fever \& discharge & 97 & 5.4 \\
\hline Prolonged labor + convulsion & 54 & 3.0 \\
\hline Excessive bleeding + fever \& discharge & 51 & 2.9 \\
\hline Excessive bleeding +convulsion & 56 & 3.1 \\
\hline Fever \& discharge + convulsion & 90 & 5.0 \\
\hline Prolonged labor + Excessive bleeding + convulsions & 68 & 3.8 \\
\hline Prolonged labor, Excessive bleeding + fever \& discharge & 42 & 2.3 \\
\hline Prolonged labor + fever \& discharge + convulsions & 33 & 1.8 \\
\hline Excessive bleeding + fever \& discharge + convulsion & 92 & 5.1 \\
\hline Prolonged labor + Excessive bleeding + fever \& discharge + & 896.0 \\
\hline convulsions & $\left(1^{\prime} 806\right)$ & 49.6 \\
\hline Total multiple cases & $\left(3^{\prime} 459\right)$ & 52.2 \\
\hline Total number of reported morbidity cases & & 100.0 \\
\hline Total number of pregnancies & & \\
\hline - & & \\
\hline
\end{tabular}

a Multiple responses were recorded.

\section{Predictors of self-reported maternal complications}

Table 8 shows the results of the binary logistic regression to determine which sociodemographic, obstetric and cultural factors predict overall self-reported maternal morbidity. Two models are presented; the first one includes assistance at delivery among the predictors, while the second does not. Given the relatively low proportion of deliveries with skilled attendant in Kenya in 1998, we anticipate that women who seek the help of qualified health professionals are more likely to do so because they suffer from maternal complications. Skilled attendance could also help women identify maternal complications. In this sense, there could be a problem of endogeneity with the variable related to assistance at delivery. However, the coefficients for the other predictors are similar in the two models, indicating that our results are robust. We observe that reports on delivery complications are not associated with maternal age and genital mutilation. Nevertheless, parity, assistance at delivery, and ethnicity are significant predictors of reporting on maternal 
morbidity. The odds of reporting increases by 1.5 when a woman has more than four children as compared to two to four children; when assisted by a qualified birth attendant the odds of reporting increases by 1.4 as compared to an unqualified attendant; and when a woman is Kisii or Luhya, the odds increases by 1.8 and 1.5, respectively, as compared to Kalenjin.

TABLE 8 Factors associated with the odds of reported maternal morbidity (multiple regression analysis)

\begin{tabular}{|c|c|c|c|c|}
\hline \multirow[t]{2}{*}{ Associated variables } & \multicolumn{2}{|c|}{ Model 1} & \multicolumn{2}{|c|}{ Model 2} \\
\hline & $\begin{array}{l}\text { Estimated } \\
\text { odds ratio }\end{array}$ & $\begin{array}{l}95 \% \mathrm{Cl} \text { for } \\
\text { odds ration }\end{array}$ & $\begin{array}{l}\text { Estimated } \\
\text { odds ratio }\end{array}$ & $\begin{array}{l}95 \% \mathrm{Cl} \text { for } \\
\text { odds ration }\end{array}$ \\
\hline \multicolumn{5}{|c|}{ Maternal age (vs 20-34) } \\
\hline$<20$ & 1.11 & $0.86-1.44$ & 1.06 & $0.83-1.36$ \\
\hline $35+$ & 0.82 & $0.62-1.09$ & 0.80 & $0.61-1.07$ \\
\hline \multicolumn{5}{|l|}{ Parity (vs 2-4) } \\
\hline 1 & $1.28 * *$ & $1.02-1.61$ & $1.35 * * *$ & $1.09-1.69$ \\
\hline $5+$ & $1.46 * * *$ & $1.17-1.82$ & $1.35^{* * *}$ & $1.09-1.68$ \\
\hline \multicolumn{5}{|c|}{ Assistance at delivery (vs unqualified) } \\
\hline Qualified & $1.35 * * *$ & $1.12-1.62$ & & \\
\hline Alone & $0.74^{* *}$ & $0.56-0.99$ & & \\
\hline \multicolumn{5}{|l|}{ Ethnicity (vs Kalenjin) } \\
\hline Kamba & 1.19 & $0.86-1.65$ & 1.17 & $0.85-1.63$ \\
\hline Kikuyu & 0.65 & $0.48-0.90$ & 0.69 & $0.51-0.94$ \\
\hline Kisii & $1.76 * * *$ & $1.23-2.51$ & $1.72 * * *$ & $1.20-2.46$ \\
\hline Luhya & $1.54 * * *$ & $1.13-2.08$ & $1.12 * *$ & $1.05-1.90$ \\
\hline Luo & 0.97 & $0.71-1.33$ & 0.93 & $0.69-1.27$ \\
\hline Somalie & 0.89 & $0.58-1.37$ & 0.85 & $0.56-1.29$ \\
\hline Other & 0.99 & $0.71-1.38$ & 1.03 & $0.75-1.42$ \\
\hline \multicolumn{5}{|c|}{ Genital mutilation (vs no) } \\
\hline Yes & 1.063 & $0.86-1.31$ & 1.03 & $0.84-1.26$ \\
\hline
\end{tabular}

\section{Discussions}

In the logistic regression analysis, a significant interaction between parity, assistance at delivery, ethnicity, and reported morbidity was found. Two models were used. In the first model, to predict reporting of maternal morbidity, maternal age, parity, genital mutilation, and ethnicity were considered as exogenous variables, while assistance at delivery was considered as endogenous, since women's reports on complications ex- 
perienced during delivery were more likely to be linked with the person who assisted them at delivery. However, in the second model, assistance at delivery was dropped in order to control for this endogeneity. No major changes were observed between the two models. In both models, the odds for self-reported morbidity increased among women with more than four children. With the likelihood of most obstetric complications increasing with maternal age and parity, grand multiparous are more predisposed to maternal complications such as hemorrhage and puerperal sepsis. Reporting on complications may be based on experiences from previous births. As stated earlier, assistance at delivery being significantly linked to self-reporting can be best explained by the fact that women who delivered with the help of a qualified birth attendant (doctor, nurse or midwife) were probably more informed about their condition as compared to those who delivered alone or with the help of an unqualified attendant. Province of residence as a predictor of self-reported morbidity is most likely influenced by women's health status, access to maternal health and level of education. These factors either increase or decrease the odds of self-reported maternal complications. Women in good health who have access to maternal health services are less likely to report complications. Equally, women with no access to maternal health or, who are less educated are also less likely to report maternal complications. There is also the effect of women's selection due to maternal mortality. Maternal mortality ratio is high among women who deliver at home with the assistance of unqualified birth attendants, primiparous women who are very young $(<15)$, and who live in the rural areas.

The KDHS 1998 survey was used in this study as a first attempt to estimate the global prevalence of self-reported maternal morbidity in Kenya and to study its determinants. The technique use to collect data on maternal morbidities was relatively easy to conduct and was administered by nonmedical personnel. The survey contributes to gaining knowledge about delivery complications among Kenyan women as a whole since it captures those who delivered in health facilities and those who did not. Its sampling design allows generalization of estimates to the entire population and comparisons between geographical regions. Information collected enables to understand determinants of self-reported morbidity. However, this approach has its limitations, as detailed earlier. It underestimates the overall prevalence of self-reported morbidities due to various biases. The validity of the self-reported morbidities depends on how accurately women recognize and recall complications experienced around the time of delivery. Some symptoms that are not perceived such as hypertension may be omitted. Then, self-reported morbidities might 
not be reliable particularly among young primiparous who may overreport symptoms. In addition, the data collection technique produces a major selection bias: questions are asked only to women who were still alive at the moment of the survey. This bias, not only affects the global measurement of maternal morbidity, but also impacts on comparisons between geographical regions. At the global level, there could be an underestimation of the magnitude of maternal morbidity. In comparison to rural areas, urban regions have generally better medical facilities, more health staff, and more deliveries occur in health facilities by skilled attendants. There will be obviously fewer maternal deaths among urban women affected by maternal morbidity. Therefore, there will be more women surviving to maternal morbidity in urban regions compared to rural regions.

\section{Conclusion}

Self-reported morbidity cannot provide entirely accurate estimates of the magnitude of maternal morbidity at both the national and regional levels. However, without a feasible data collection technique on all deliveries in developing countries, self-reports in response to well-designed and well-worded interviews may be the only way to collect information about maternal morbidity. Notwithstanding data quality issues inherent to this technique, maternal morbidity data collected through population-based survey like DHS could be used in combination to provide a better understanding of severe complications. For instance, combining prolonged labor, one of the medical causes of hemorrhage, with excessive bleeding, could increase the sensitivity of hemorrhage. Prolonged labor could also be combined with fever and foul smelling discharge to estimate puerperal sepsis.

\section{References}

AвouZahr C. (2003), "Global Burden of Maternal Death and Disability», Br. Med. Bull., 67, pp. 1-11, http://dx.doi.org/10.1093/bmb/ldg015.

Adams M. M., Alexander G. R., Kirby R. S., Wingate M. S. (2010), Perinatal Epidemiology for Public Health Practice, Springer. 
Ali A. A., Khojali A., Okud A., Adam G. K., Adam I. (2011), "Maternal Near-Miss in a Rural Hospital in Sudan", BMC Pregnancy Childbirth, 11, pp. 1-4, http://dx.doi.org/ 10.1186/1471-2393-11-48.

amaral E., Souza J. P., Surita f., luz A. G., Sousa M. H., Cecatti J. G., Campbell O. (2011), «A Population-Based Surveillance Study on Severe Acute Maternal Morbidity (Near-Miss) and Adverse Perinatal Outcomes in Campinas, Brazil», The Vigimoma Project. BMC Pregnancy Childbirth, 11, pp. 1-8, http://dx.doi.org/10.1186/14712393-11-9.

Ashford L., (Project) M. C. (2002), «Hidden Suffering: Disabilities from Pregnancy and Childbirth in Less Developed Countries", Population Reference Bureau, MEASURE Communication.

Balin R. E. (2005), Trends in Midwifery Research, Nova Publishers.

Calvert C., Thomas S. L., Ronsmans C., Wagner K. S., Adler A. J., Filippi V. (2012), Identifying Regional Variation in the Prevalence of Postpartum Haemorrhage: $A$ Systematic Review and Meta-Analysis, PLOS ONE 7, http://dx.doi.org/10.1371/ journal.pone.0041114.

Campbell O. M., Graham W. (1990), Measuring the Determinants of Maternal Morbidity and Mortality.

Chersich M. F., Kley N., luchters S. M., NJeru C., Yard E., Othigo M. J., Temmerman M. (2009), "Maternal Morbidity in the First Year After Childbirth in Mombasa Kenya; A Needs Assessment», BMC Pregnancy Childbirth, 9, pp. 1-10, http://dx.doi. org/10.1186/1471-2393-9-51.

Chhabra P., Guleria K., Saini N. K., ANJur K. T., Vaid N. B. (2008), «Pattern of Severe Maternal Morbidity in a Tertiary Hospital of Delhi, India: A Pilot Study», Trop. Doct., 38, pp. 201-204, http://dx.doi.org/10.1258/td.2007.070327.

Cleland J., Harlow S. (2003), "The Value of the Imperfect: The Contribution of Interview Surveys to the Study of Gynaecological III Health», S. JeJEebHoY, M. KoENIG, C. ELIAS (eds), Investigating Reproductive Tract Infections and Other Gynaecological Disorders: A Multidisciplinary Research Approach, Cambridge University Press, Cambridge, pp. 283-321.

Dolea C., AbouZahr C. (2003), "Global Burden of Obstructed Labor in the Year 2000», GDB Working Paper, World Health Organisation, Geneva.

Dolea C., Stein C. (2003), "Global Burden of Maternal Sepsis in the Year 2000», GDB working paper, World Health Organisation, Geneva.

Eluison G. T., De Wet T., Matshidze K. P., Cooper P. (2000), «The Reliability and Validity of Self-Reported Reproductive History and Obstetric Morbidity Amongst Birth to Ten Mothers in Soweto", Curationis, 23, pp. 76-80, http://dx.doi.org/10.4102/ curationis.v23i4.753. 
Filippi V., Ganaba R., Baggaley R. F., Marshall T., Storeng K. T., Sombié I., Ouattara F., Ouedraogo T., Akoum M., Meda N. (2007), "Health of Women After Severe Obstetric Complications in Burkina Faso: A Longitudinal Study", Lancet, 370, pp. 1'3291 '337.

Filipi V., Ronsmans C., Gandaho T., Graham W., Alihonou E., Santos P. (2000), "Women's Reports of Severe (Near-Miss) Obstetric Complications in Benin», Stud. Fam. Plann., 31, pp. 309-324, http://dx.doi.org/10.1111/j.1728-4465.2000.00309.x.

FortneY J., SMITH J. (1999), "Measuring Maternal Morbidity», M. Berer, T. K. S. Ravindran (eds), Safe Motherhood Initiatives; critical Issues, Oxford. England, Blackwell Science, Reproductive Health Matters special issue.

Furuta M., SANDAll J., Bick D. (2012), A Systematic Review of the Relationship Between Severe Maternal Morbidity and Post-Traumatic Stress Disorder, BMC Pregnancy Childbirth, 12, $125 \mathrm{p}$.

haddad S. M., Cecatti J. G., Parpinell M. A., Souza J. P., Costa M. L., Sousa M. H., Surita F. G., Silva J. L. P., Pacagnella R. C., Camargo R. S., Bahamondes M. V., Zotareli V., Gurgel L. T., SAY L., Pattinson R. C. (2011), From Planning to Practice: Building the National Network for the Surveillance of Severe Maternal Morbidity, BMC Public Health, 11, 283 p.

HARDEe K., GaY J., Blanc A. K. (2012), «Maternal Morbidity: Neglected Dimension of Safe Motherhood in the Developing World», Glob. Public Health, 7, pp. 603-617, http://dx.doi.org/10.1080/17441692.2012.668919.

Kaye D. K., KaKaIRE O., Osinde M. O. (2011), «Systematic Review of the Magnitude and Case Fatality Ratio for Severe Maternal Morbidity in Sub-Saharan Africa Between 1995 and 2010», BMC Pregnancy Childbirth, 11, pp. 1-9, http://dx.doi.org/ 10.1186/1471-2393-11-65.

Kayem G., Kurinczuk J., LeWis G., Golightly S., Brocklehurst P., KNight M. (2011), «Risk Factors for Progression from Severe Maternal Morbidity to Death: A National Cohort Study», PLOS ONE 6, http://dx.doi.org/10.1371/journal.pone.0029077.

Khan K. S., Wojdyla D., SAY L., Gülmezoglu A. M., VAN Look P. F. (2006), "WHO Analysis of Causes of Maternal Death: A Systematic Review», The Lancet, 367, pp. 1'066-1'074.

Koblinsky M., Chowdhury M. E., Moran A., Ronsman C. (2012), Maternal Morbidity and Disability and Their Consequences: Neglected Agenda in Maternal Health.

Koenig M. A., Jamil K., Streatfield P. K., Saha T., Al-Sabir A., Arifeen S. E., Hill K., HAQUE Y. (2007), "Maternal Health and Care-Seeking Behavior in Bangladesh: Findings from a National Survey», Int. Fam. Plan. Perspect., 33, pp. 75-82, http://dx.doi. org/10.1363/3307507.

KWAST B. E. (1991), «Postpartum Haemorrhage: Its Contribution to Maternal Mortality», Midwifery, 7, pp. 64-70, http://dx.doi.org/10.1016/S0266-6138(05)80229-3. 
LISKIN L. S. (1992), "Maternal Morbidity in Developing Countries: A Review and Comments», Int. J. Gynaecol. Obstet. Off. Organ Int. Fed. Gynaecol. Obstet., 37, pp. 77-87, http://dx.doi.org/10.1016/0020-7292(92)90486-3.

MidHet F. (2007), «Prevalence and Determinants of Self-Reported Morbidity Among Pregnant Women in Rural Areas of Pakistan», Int. J. Health Sci., 1, pp. 243-248.

Nelissen E. J., Mduma E., Ersdal H. L., Evjen-Olsen B., Roosmalen J. J. van, StekelenBURG J. (2013), "Maternal near Miss and Mortality in a Rural Referral Hospital in Northern Tanzania: A Cross-Sectional Study», BMC Pregnancy Childbirth, 13, pp. 110, http://dx.doi.org/10.1186/1471-2393-13-141.

Nour N. M. (2008), «An Introduction to Maternal Mortality», Rev. Obstet. Gynecol., 1, pp. 77-81.

Nyaboga E. O. (2009), Maternal mortality at Kenyatta National' hospital (Nairobi, Kenya) 2000-2008, Thesis.

Nyblade L., Edmeades J., Pearson E. (2010), «Self-Reported Abortion-Related Morbidity: A Comparison of Measures in Madhya Pradesh, India», Int. Perspect. Sex. Reprod. Health, 36, pp. 140-148, http://dx.doi.org/10.1363/3614010.

Oduro A., Ansah P., Hodgson A., Afful T., Baiden F., Adongo P., Koram K. (2006), "Trends in the Prevalence of Female Genital Mutilation and its Effect on Delivery Outcomes in the Kassena-Nankana District of Northern Ghana», Ghana Med. J., 40, pp. 87-92.

Oladapo O. T., Sule-Odu A. O., Olatunj A. O., Daniel O. J. (2005), «'Near-Miss' Obstetric Events and Maternal Deaths in Sagamu, Nigeria: A Retrospective Study. Reprod», Health, 2, pp. 1-9.

Ronsmans C., Achad E., Cohen S., ZazRi A. (1997), "Women's Recall of Obstetric Complications in South Kalimantan, Indonesia», Stud. Fam. Plann., 28, pp. 203-214, http://dx.doi.org/10.2307/2137888.

SAdANA R. (2000), "Measuring Reproductive Health: Review of Community-Based Approaches to Assessing Morbidity», Bull. World Health Organ., 78, pp. 640-654.

Saucedo M., Deneux-Tharaux C., Bouvier-Colle M.-H. (2013), «Épidémiologie de la mortalité maternelle en France, 2007-2009», J. Gynécologie Obstétrique Biol. Reprod., 42, pp. 613-627, http://dx.doi.org/10.1016/j.jgyn.2013.06.011.

Say L., Chou D., Gemmill A., Tunçalp Ö., Moller A.-B., Daniels J., Gülmezoglu A. M., Temmerman M., Alkema L. (2014), «Global Causes of Maternal Death: A WHO Systematic Analysis», Lancet Glob. Health, http://dx.doi.org/10.1016/S2214-109X(14) 70227-X.

Say L., Pattinson R. C., Gülmezoglu A. M. (2004), WHO Systematic Review of Maternal Morbidity and Mortality: The Prevalence of Severe Acute Maternal Morbidity (Near Miss), Reprod. Health, 1, 3 p. 
Say L., Souza J. P., Pattinson R. C., WHO Working group on Maternal Mortality and MORBIDITY CLASSIFICATIONS (2009), "Maternal Near Miss-Towards a Standard Tool for Monitoring Quality of Maternal Health Care», Best Pract. Res. Clin. Obstet. Gynaecol., 23, pp. 287-296, http://dx.doi.org/10.1016/j.bpobgyn.2009.01.007.

SeoAne G., CAstrillo M., O’Rourke K. (1998), «Validation Study of Maternal Self Reports of Obstetrical Complications: Implications for Health Surveys», 62, pp. 229236, http://dx.doi.org/10.1016/s0020-7292(98)00104-0.

Sloan N. L., Amouaful E., Arthur P., Winikoff B., Adjei S. (2001), "Validity of Women's Self-Reported Obstetric Complications in Rural Ghana», J. Health Popul. Nutr., 19, pp. 45-51.

Sousa M. H., Cecatti J. G., Hardy E. E., Serruya S. J. (2008), "Severe Maternal Morbidity (Near Miss) as a Sentinel Event of Maternal Death. An Attempt to Use Routine Data for Surveillance», Reprod. Health, 5, pp. 1-8, http://dx.doi.org/10.1186/ 1742-4755-5-6.

Souza J. P., Cecatti J. G., Pacagnella R. C., Giavarotti T. M., Parpinelli M. A., CAMARGO R. S., SOUSA M. H. (2010), «Development and Validation of a Questionnaire to Identify Severe Maternal Morbidity in Epidemiological Surveys», Reprod. Health, 7, pp. 1-9, http://dx.doi.org/10.1186/1742-4755-7-16.

Souza J. P., Sousa M. H. de, Parpinell M. A., Amaral E., Cecatti J. G. (2008), «SelfReported Maternal Morbidity and Associated Factors Among Brazilian Women", Rev. Assoc. Médica Bras., 1992 (54), pp. 249-255, http://dx.doi.org/10.1590/S010442302008000300019.

Stewart M. K., Festin M. (1995), «Validation Study of Women's Reporting and Recall of Major Obstetric Complications Treated at the Philippine General Hospital», Int. J. Gynaecol. Obstet. Off. Organ Int. Fed. Gynaecol. Obstet., 48 Suppl, pp. S53-66, http://dx.doi.org/10.1016/0020-7292(95)02320-C.

Stewart M. K., Stanton C. K., Festin M., Jacobson N. (1996), «Issues in Measuring Maternal Morbidity: Lessons from the Philippines Safe Motherhood Survey Project», Stud. Fam. Plann., 27, pp. 29-35, http://dx.doi.org/10.2307/2138075.

Thaddeus S., Maine D. (1994), "Too Far to Walk: Maternal Mortality in Context», Soc. Sci. Med., 38, pp. 1'091-1'110, http://dx.doi.org/10.1016/0277-9536(94)90226 $-7$.

Ukachukwu V. E., Unger H., Onoka C., Nduka C., Maina S., Ngugi N. (2009), «Maternal Morbidity and Mortality in Peri-Urban Kenya-Assessing Progress in Improving Maternal Healthcare», East Afr. J. Public Health, 6, pp. 112-118.

Who, Banks E., MeiriK O., Farley T., Akande O., Bathija H., Ali M. (2006), «Female Genital Mutilation and Obstetric Outcome: WHO Collaborative Prospective Study in Six African Countries», Lancet, 367, pp. 1'835-1'841.

Yamin A. E., Maine D.P. (1999), «Maternal Mortality as a Human Rights Issue: Measuring Compliance with International Treaty Obligations», Hum. Rights Q., 21, pp. 563-607, http://dx.doi.org/10.1353/hrq.1999.0046. 
Yego F., Williams J. S., Byles J., Nyongesa P., Aruasa W., D’Este C. (2013), A Retrospective Analysis of Maternal and Neonatal Mortality at a Teaching and Referral Hospital in Kenya, Reprod. Health, 10, 13 p.

Ziraba A. K., Madise N., Mills S., Kyobutungi C., Ezeh A. (2009), Maternal Mortality in the Informal Settlements of Nairobi City: Whay Do we Know? 